\title{
Los judíos del Cáucaso en Israel. Una inmigración invisibilizada.
}

\author{
The Jews of the Caucasus in Israel. An invisible immigration.
}

\author{
Manuel Férez. \\ ferezmanuel@yahoo.com \\ Universidad Alberto Hurtado.
}

"Entre las riquezas y placeres de la gozosa Asia me encuentro como un viajero pobre y fatigado; cuando estoy rodeado de abundancia de oro y la fertilidad de la ardiente África, me siento un miserable exiliado, famélico y sediento. Y en cuanto a ti, Europa, oh Europa, mi infierno en la Tierra, ¿qué diré de ti?" Samuel Usque. Consuelo de las tribulaciones de Israel.

\section{RESUMEN}

Este artículo tiene como objetivo principal el describir los procesos migratorios de los judíos del Cáucaso hacia Israel así como abordar las tensiones, estrategias de integración y/o asimilación enfocándose en los mecanismos de preservación y transmisión de los valores culturales propios de los judíos del Cáucaso emigrados a Israel a finales del siglo XX

Palabras claves: Judíos, Caucaso, inmigración, invisibilización judíos del Causcasus

\section{ABSTRACT}

This article has as main objective to describe the migratory processes of the Jews of the Caucasus towards Israel as well as to address the tensions, integration and / or assimilation strategies focusing on the mechanisms of preservation and transmission of the cultural values of the Jews of the Caucasus emigrated to Israel at the end of the 20th century

Keywords Jews, Caucasus, immigration, invisibility Jews of the Caucasus

\section{Introducción}

El Cáucaso, zona montañosa atrapada durante gran parte de su historia entre poderosos imperios y ubicada entre el Mar Negro y el Caspio, fue por miles de años refugio para naciones y tribus perseguidas incluidos judíos que encontraron en sus montañas un lugar para preservar sus costumbres, idiomas, creencias y prácticas religiosas. ${ }^{1}$ Durante siglos la zona caucásica siguió un

\footnotetext{
${ }^{1}$ Para un primer acercamiento al Cáucaso recomiendo el libro de Thomas de Waal "The Caucasus. An Introduction”. Oxford University Press. 2010.
} 
derrotero particular pues si bien estaba condicionada por imperios poderosos, su geografía permitió el desarrollo de particularismos religiosos, étnicos y lingüísticos que aún en nuestros días son percibidos, atesorados y transmitidos intergeneracionalmente.

A partir de la desintegración de la Unión Soviética se generó una dinámica migratoria sin precedentes en la historia del Cáucaso: la emigración masiva hacia Israel, Estados Unidos y Rusia de sus judíos. Es cierto que esta movilización poblacional resultó minoritaria en relación al grueso de población judía de origen ruso que abandonó la región en el mismo periodo de tiempo y debido al predominio de "lo ruso" las especificidades de la población judía caucásica pasaron desapercibidas.

Este artículo tiene como objetivo principal el describir los procesos migratorios de los judíos del Cáucaso hacia Israel así como abordar las tensiones, estrategias de integración y/o asimilación enfocándose en los mecanismos de preservación y transmisión de los valores culturales propios de los judíos del Cáucaso emigrados a Israel a finales del siglo XX.

Si bien la motivación del artículo es acercar al lector hispanohablante a la historia y dinámicas actuales de los judíos del Cáucaso emigrados a Israel, la misma exposición llevará a la discusión sobre la cuestión ¿Cuáles son las razones de la invisibilización de los judíos caucásicos en el contexto judío mundial en general y en la academia dedicada a los estudios judaicos en particular?

La hipótesis que propongo es la siguiente: la invisibilización de la migración de los judíos del Cáucaso a Israel se debe a dos fenómenos paralelos pero complementarios: por un lado responde a la tendencia analítica de integrar a las "migraciones invisibilizadas y subsumidas" dentro de un grupo mayoritario y diferenciado hacia un país (en este caso Israel) que carece de políticas y administración adecuadas para abordar las especificidades de este grupo y por otro lado, la propia tendencia de los estudios judaicos en América Latina que han sido dominados por una visión eurocéntrica en la cual la Shoa juega un rol central y que ha marginado de la academia a otras dinámicas y grupos judíos que se perpetúa por la ausencia de académicos provenientes del Cáucaso en las universidades y centros de investigación en Latinoamérica.

En este sentido, y a manera de ejemplo, es interesante constatar que en la obra de Paul Johnson "La historia de los judíos" en sus más de 700 páginas sólo tiene dos breves menciones sobre el Cáucaso y sus judíos. En el mismo tenor Simón Dubnow en su "Manual de la Historia Judía" y Simón Schama en "La Historia de los Judíos", obras extraordinarias y de amplia circulación en Europa y América, dedican unas pocas, y a veces sesgadas, líneas a los judíos caucásicos.

El artículo se basa en una investigación cualitativa, con un enfoque hermenéutico- dialéctico (Gurdián, 2007), en tanto busca interpretar prácticas de sujetos desde los mismos en un momento socio histórico específico. El trabajo de campo se realizó entre junio 2014 a junio 2018, en el cual se combina una observación de campo de dos meses en Azerbaiyán y Georgia de las dinámicas cotidianas de 5 personas y sus familias, visitas a las sinagogas de Bakú, al museo judío de Tbilisi y al cementerio general de Bakú y 15 entrevistas a profundidad que siguieron siendo monitoreadas por cuatro años de manera virtual. Los datos fueron abarcados desde el análisis de contenido buscando levantar categorías según el relato de los sujetos y el material simbólico observado (Díaz, 2018). 


\section{Historia y geografía de los judíos del Cáucaso}

A nivel geográfico, se puede entender esta zona entre Ciscaucasia (el norte del Cáucaso) compuesta por Chechenia, Osetia, Daguestán, Ingusetia, Kabardino Balkaria, Cherkesia, Circasia, Calmuca, Karachi, Nogai y Adigueya y lo que los rusos denominan Transcaucasia (el sur del Cáucaso) formada por Georgia, Armenia, Azerbaiyán, Abjasia y Adzaria. ${ }^{2}$ Es una zona de alta densidad étnica, lingüística y religiosa en la que coexisten 20 etnias diferenciadas y más de 70 lenguas y dialectos, además de otros mestizajes y otros pueblos pequeños que otorgan al Cáucaso su particularidad regional ante sus vecinos que han tendido a la homogeneización. ${ }^{3}$

La llegada de los judíos a esta región está rodeada de mitos y leyendas entre las que destacan aquellas de la literatura armenia y georgiana que los relacionan con las diez tribus perdidas de Israel. Otros mitos, que aún circulan entre los ancianos judíos del Cáucaso, se basan en menciones en el Talmud y el exilio posterior a la destrucción del Segundo Templo. Historiadores armenios como Moisés de Chorene (siglo V) y Fausto Bizantino (siglo IV) relataron la llegada de judíos al territorio de la actual Armenia y Georgia desde Babilonia y Persia.

Una de las características identitarias particulares de los judíos caucásicos es su idioma. El Ju hurí (judeo tati) es un dialecto hablado por los judíos de la montaña del sector oriental de la cordillera del Cáucaso, Azerbaiyán y Daguestán. Lingüísticamente este dialecto está relacionado con el farsi y tanto musulmanes como cristianos de la zona emplean un lenguaje parecido aunque con más influencia árabe y persa que aquel hablado por los judíos que tiene préstamos del hebreo y arameo.

Las conquistas árabe/musulmanas del siglo VIII en el Cáucaso, a expensas de pequeños y desunidos reinos cristianos, alteraron las dinámicas en la región y afectaron a las comunidades judías, registrándose conversiones de judíos al Islam y migraciones a regiones de Asia Central y Medio Oriente.

El Imperio Jázaro ${ }^{4}$ durante los siglos VII y IX incluyó partes del Cáucaso del norte siendo un lugar de migración de judíos que huían de las persecuciones cristiana y musulmana. Historiadores como el musulmán Masudi y el cronista caraíta Al Kirkisani relatan cómo en este Kanato independiente, el judaísmo llegó a ser la religión oficial y se registraron conversiones al judaísmo entre las castas dirigentes. Si bien dicho Imperio inició su declive en el siglo X los viajeros y cronistas Benjamín de Tudela y Guillermo Rubruquis se encontraron, dos siglos después del fin del Imperio Jázaro, con

\footnotetext{
${ }^{2}$ Esta diferenciación refleja el punto de vista ruso sobre la región.

${ }^{3}$ Etnias del Cáucaso:

Indígenas: Georgianos, Adygués, Abjasios, Chechenos, Ingusetios, Circasianos, Ubyjs, Bats, Lezguis, Avaros, Andilaks, Darwas, Archis, Aghuls, Tsahurs, Lazs, Megrelios, Svans, Ghodoberis, Abazos, Mesjets y Tats. -Eslavos: Rusos y Ucranianos.

-Iranianos: Osetios, Armenios, Kurdos, Kurmandys, Domaris y Talysh.

-Altaicos: Calmucos, Azerbayanos, Daghestanos, Kumykos, Karachis, Kabardos, Cherkeses, Balkares, Nogais, Turcos y Persas.

-Otros: Alemanes, Griegos, Búlgaros y Judíos.

${ }^{4}$ Sobre el Imperio Jázaro sugiero consultar "The Khazars: A Judeo-Turkish Empire on the Steppes, 7th-11th" de David Nicolle y "The Jews of Khazaria" de Kevin Allan Brook.
} 
algunos judíos en las montañas de la actual Georgia y en el Monte Ararat que mantenían tradiciones religiosas particulares y antiquísimas.

Las conquistas mongolas del Cáucaso durante el siglo XIII marcaron un momento coyuntural al interrumpir el comercio entre el Cáucaso y Europa, afectando especialmente a las comunidades judías que habían establecido una red comercial, religiosa e identitaria a lo largo de la región. ${ }^{5}$ De hecho, entre los siglos XIII y XVII no se encuentran documentos historiográficos fidedignos sobre las comunidades judías dado que el dominio mongol destruyó cualquier tipo de registro histórico, a lo que se suma la desarticulación de las comunicaciones entre las comunidades judías.

Las conquistas rusas de fines del siglo XVIII darían fin a un largo periodo de caos y violencia en el Cáucaso causada por los mongoles. Hay que indicar que una reacción a estas invasiones rusas fue el fanatismo musulmán contra judíos y cristianos liderado por los Murids, secta islámica radical que lucharía contra la invasión rusa y desataría una yihad en el Cáucaso. En aquellos pueblos y villas en donde los judíos no podían abandonar sus tierras se registraron conversiones al Islam que no implicaron el abandono de creencias y costumbres judías. (Kaganovitch, 2011)

El siglo XIX fue testigo de la conquista rusa de la gran mayoría del Cáucaso, sin embargo, lo que prometía ser un periodo de estabilización y bienestar para las comunidades judías se vio envenenado por el anti judaísmo del zar Nicolás I quien decretó una orden de expulsión de judíos y enviada a los principales líderes locales, que permitían y facilitaban el control ruso de la región. En un hecho histórico extraordinario esos líderes locales, aliados del zar, le replicaron unánimemente pidiéndole no implementar la orden de expulsión pues los judíos restantes (alrededor de 15 mil personas) se hallaban integrados a la vida de la región y eran parte importante en ella.

Los judíos sobrevivientes y que fueron defendidos por sus líderes locales eran principalmente agricultores, artesanos, pequeños comerciantes y siervos de terratenientes. En 1837 se ratificó el Derecho de Residencia para judíos nacidos en el Cáucaso aunque el ingreso de judíos de otras regiones del imperio y la residencia de esos judíos caucásicos en otras zonas siguieron prohibidos hasta 1860 cuando se permitió la residencia más allá de la "zona de asentamiento" lo que propició la llegada masiva de judíos rusos al Cáucaso que agregaron complejidad y alterarían el balance demográfico intra comunitario.

Los años fines del siglo XIX resultaron ser un momento paradigmático en la vida judía del Cáucaso pues los judíos rusos recién llegados se incorporaron a los estratos medios y altos de la estructura social de la región y gradualmente desplazaron a los judíos nativos a estratos sociales inferiores y menos visibles internacionalmente, ejemplo de lo anterior es que fueron empresarios judíos rusos los que participaron en el desarrollo y explotación de los campos petroleros de Bakú así como en el trazado, financiación e implementación del proyecto ferroviario ruso en la zona caucásica.

Debido a este proceso migratorio ruso, la composición étnica de la comunidad judía en el Cáucaso experimentó un vuelco para mediados del siglo XIX, pues ya en 1857 se contabilizaban 56,773

\footnotetext{
${ }^{5}$ El periodo mongol y los setenta años de dominio soviético son los únicos momentos históricos de aislamiento total del Cáucaso, región que tiende a la apertura comercial. En el siglo XXI las tres repúblicas independientes del sur del Cáucaso buscan insertar a sus países internacionalmente.
} 
judíos en el Cáucaso de los cuales 43, 390 eran askenazíes (Yiddish como lengua materna) mientras que sólo 7,038 eran judíos de la montaña y 6,034 judíos georgianos. (Bram, 2009).

Con la llegada de los judíos rusos y su inserción en la vida económica de la zona se reestablecieron y ampliaron los contactos comerciales y culturales de los judíos del Cáucaso con las comunidades judías rusas, otomanas y persas. Además de la reactivación económica aparecieron ideologías desconocidas entre los judíos caucásicos, entre ellas el pensamiento sionista que trastocó tanto las relaciones intracomunitarias como aquellas que se mantenían con los líderes locales y las autoridades zaristas.

El Cáucaso funcionó de 1917 hasta 1920 como una zona de tránsito de judíos hacia la Palestina otomana. En 1921 cuando los soviéticos bolcheviques establecieron su dominio en la región comprendieron que una manera de mantener tranquila a la población era no ofender el sentimiento religioso de sus habitantes por lo que los judíos del Cáucaso mantuvieron sus costumbres, tradiciones, lenguajes y no experimentaron un proceso de rusificación, más allá de aprender ruso como la lengua franca regional.

Si bien el judeo tati fue objeto de políticas que buscaban inhibir su uso y transmisión en detrimento del ruso, el dialecto se fortaleció en su uso familiar y cotidiano, constituyéndose como una práctica de resistencia y distinción respecto al ruso como idioma dominante. Hay que agregar que los soviéticos intentaron definir a los judíos del Cáucaso como étnicamente "tats" (parte de la "nacionalidad tat" que incluía también a tats musulmanes y tats cristianos armenios) para así aislarlos del judaísmo occidental. ${ }^{6}$

Lo anterior generó la siguiente complejidad que tiene implicaciones políticas e identitarias tanto en el Cáucaso como en los países a los cuales han emigrado ¿son los judíos, cristianos y musulmanes hablantes del tati un grupo étnico religiosamente diferenciado o son grupos étnico/religiosos diferenciados que comparten una lengua común?

La política soviética buscaba establecer que los judíos tats sólo eran judíos por sus prácticas religiosas, por lo que no tenían conexión histórica, cultural ni genética con el mundo judío en general, esto tenía como objetivo aislarlos de las dinámicas sionistas que proponían un origen semítico común a todos los judíos del mundo. Esto ha generado una pseudo academia que desliga a los judíos askenazíes del mundo semítico, basándose en el ya mencionado Imperio Jázaro y las conversiones al judaísmo registradas durante el mismo, para elaborar sus teorías raciales (descalificadas por la mayoría de los trabajos genéticos serios).

La etnografía soviética encontró en el Cáucaso una región de gran interés académico y por primera vez se establecieron centros de investigación antropológica sobre los judíos de la zona que, para 1959, publicaron la siguiente descripción demográfica judía: 125,000 judíos en el Cáucaso (1\% de la población) ubicados principalmente en Georgia, Azerbaiyán, Armenia, Daguestán, KabardinoBalcaria, Osetia del Norte y Chechenia. De esos 125 mil 35,000 eran georgianos, 25,000 judíos de la montaña, 65,000 judíos rusos siendo los mayores centros de concentración poblacional judía las ciudades de Bakú $(26,623)$ y Tbilisi $(17,311)$.

\footnotetext{
${ }^{6}$ Sobre el judeo tat sugieron consultar "The Language of Caucasus Jews" de Chen Bram y "Judeo-Iranian Languages" de Habib Borjian.
} 


\section{Emigración a Israel}

Israel es por definición una sociedad de inmigrantes. El país, fundado oficialmente en 1948 pero que estableció instituciones, asentamientos y partidos políticos décadas antes, también empezó a recibir oleadas migratorias desde fines del siglo XIX. Dichas oleadas migratorias conocidas en hebreo como Alyot $^{7}$ han delineado los perfiles sociales y culturales del Estado.

Sobre la demografía y el proceso poblacional israelí se puede argumentar que son dos los principales grupos nacionales que componen al país, los judíos como grupo mayoritario y la minoría árabe que compone un $20 \%$ del total poblacional. Ambos grupos son profundamente heterogéneos internamente y se diferencian por características sociales y demográficas aunque, de manera general, se puede sostener que el contexto socioeconómico israelí es el de un país con un muy alto índice de desarrollo humano aunque con brechas socioeconómicas profundas que adquieren connotaciones étnico/nacionales.

En un primer momento la inmigración provino de Europa central y del este, generación conocida como la de los "padres fundadores" al ser la creadora del Estado y sus instituciones (así como de la idea de un "nuevo judío" que sería el israelí moderno y respondía a lo postulado por Herzl). Posteriormente continuaron llegando oleadas migratorias de zonas como Medio Oriente y Norte de África (década de los 50s del siglo XX) que tuvieron una impronta demográfica y social. Las últimas oleadas migratorias provinieron de Etiopía y de los países de la ex Unión Soviética que agregaron más complejidad al entramado social israelí.

Actualmente hay gran diversidad de estudios sobre las consecuencias socioeconómicas de las migraciones así como los intentos gubernamentales por cerrar las brechas educativas, culturales y laborales entre los sectores poblacionales. La gran mayoría coincide en que el estamento ashkenazí, a pesar de no ser ya mayoritario, sigue teniendo una posición dominante en relación a los judíos mizrahim, etíopes y rusos que se mantienen en los márgenes de la sociedad, comercio, academia y política.

Me parece útil la catalogación de Baruch Kimmerling de la población israelí para visualizar de manera clara los intragrupos judíos y el sector árabe:

1- Judíos askenazíes.- Componen la élite cultural del país aunque gradualmente han ido perdiendo peso demográfico y político. Se ubican principalmente en el área metropolitana de Tel Aviv y en kibbutzim. ${ }^{8}$

2- Judíos sefaradíes.- Descendientes de inmigrantes del mundo árabe/musulmán, mayoritariamente de clase media han ganado peso político y demográfico. Resienten el dominio askenazi del establishment. Votantes de derecha.

\footnotetext{
${ }^{7}$ Alyot es el plural de alyah que viene del verbo "subir" en hebreo. Con una connotación espiritual por siglos, hoy denota la inmigración de judíos a Israel.

${ }^{8}$ Kibbutzim, plural de kibutz "agrupación" en hebreo. Comunas agrícolas de corte socialista que fueron la base de la creación del Estado de Israel.
} 
3- Judíos ultraortodoxos.- Grupo demográficamente grande, en su origen con posturas anti sionista, tienden a validar a sus líderes religiosos sobre las leyes nacionales. No prestan servicio militar y cuentan con instituciones educativas y culturales separadas. Divididos internamente por orígenes étnicos suelen ser de bajos recursos económicos.

4- Judíos nacionalistas religiosos.- Con un crecimiento demográfico importante son la base del movimiento de colonización en territorios ocupados, interpretan el sionismo desde una óptica mesiánica religiosa. Viven en Jerusalén y asentamientos en Cisjordania.

5- Judíos rusos.- Inmigrados durante la década de los 90s del siglo XX siguen viviendo en enclaves culturales (ciudades y barrios) propios en donde el ruso se utiliza igual o más que el hebreo. Enfrentan problemas con el estamento religioso y luchan políticamente por establecer un registro civil secular (en Israel el único matrimonio válido es el religioso). (Tolts, 2016)

6- Árabes.- Cuentan con su propia subcultura en villas, pueblos y ciudades. Se componen de drusos, cristianos y musulmanes. Se perciben como una minoría nacional y víctimas del sionismo, se identifican como palestinos ciudadanos de Israel con su propio sistema educativo. Suelen ser bilingües (árabe y hebreo son los dos idiomas oficiales del Estado). Enfrentan discriminación, confiscación de tierras y acoso por parte del Estado.

A esos seis grupos dominantes se suman como subgrupos los judíos etíopes, los beduinos (subgrupo de la sociedad árabe), los trabajadores migrantes de África, Asia y América del Sur que no son ciudadanos del Estado y, por supuesto, a los judíos del Cáucaso (subgrupo del grupo dominante ruso).

Kimmerling sostenía que las políticas del Estado en relación a la inmigración han fluctuado de un melting pot de tipo norteamericano a un multiculturalismo fraccionado y politizado por lo que se ha transitado de la búsqueda de una sociedad homogénea a un reconocimiento de la diversidad que lleva a la siguiente pregunta ¿la sociedad israelí fragmentada y dividida fomenta la diversidad o es dicha diversidad la que fragmenta y divide?

Tanto en el sistema político como en la sociedad israelí predominan una serie de categorías construidas basadas en los orígenes geográficos de su población que, como el caso de los judíos del Cáucaso demuestra, están lejos de representar diferencias étnicas rígidas pero siguen siendo utilizadas en el diseño de las políticas de integración y en el debate público israelí. Entre esas categorías están "sefaradí", "mizrahim", "beta Israel” y "askenazi”"como marcas diferenciadoras de subgrupos del componente poblacional judío israelí.

Lo que ha sido complicado de eliminar en las políticas migratorias en Israel es lo que Javier de Lucas define como la "estigmatización de la diferencia cultural"10 que pretende (a veces veladamente) la asimilación a la cultura ashkenazí dominante y el abandono de características culturales propias del grupo inmigrante. En el caso de los judíos caucásicos se enfrentan a una doble estigmatización: la de ser inmigrantes a un nuevo Estado y la del grupo ruso dominante dentro del cual inmigraron.

\footnotetext{
${ }^{9}$ Sefaradím- judíos descendientes de España. Mizrahim- judíos orientales (originarios de países árabes). Beta Israel- judíos etíopes. Ashkenazim- judíos originarios de Europa del Este.

${ }^{10}$ De Lucas, 2003: 1.
} 
Al ser un país fundado por inmigrantes y que a lo largo de su historia ha recibido oleadas migratorias provenientes de todas partes del mundo, Israel mantiene un excepcionalmente alto índice de crecimiento poblacional emparejado a un cambio rápido motivado por las olas migratorias ya citadas sumadas a los cambios en la tasa de natalidad y mortalidad. Especialistas como Barbara $\mathrm{S}$ Okun y Eliyahu Ben Moshe han definido a Israel como un Estado "con un comportamiento demográfico heterogéneo"11.

Abdelmalek Sayad plantea le tensión entre el "orden nacional" y las dinámicas migratorias contemporáneas que desafían dicho orden. El caso de Israel presenta una diferencia al análisis de Sayad pues el Estado desde su creación se planteó como un homeland al cual los judíos del resto del mundo optarían a regresar por lo que el esquema nacional-inmigrante se anula por lo menos teóricamente. La Ley del Retorno, aprobada por la Knesset (Parlamento) israelí en 1950 establece que "todo judio, quien quiera que sea, tiene el derecho de venir a Israel en condición de Oléh (judío que inmigra a Israel) y adquirir la ciudadanía israelí." ${ }^{12}$ Bajo esta lógica, todos los judíos llegados a Israel obtienen los mismos derechos y obligaciones y participan de la misma manera en la vida social, cultural y política del país.

El "orden nacional" israelí se perfilaba como un país abierto a la inmigración judía y que daría cabida a toda expresión cultural de la diáspora. En realidad lo que ocurrió fue que una cultura dominante, la ashkenazí, se impuso en todos los sectores de la vida a otras manifestaciones culturales y tendió a asimilarlas. Las resistencias a dicha tensión se suelen centrar en una reafirmación de los valores culturales propios del subgrupo judío.

Cada subgrupo de la población judía en Israel, si bien mantiene sus artefactos culturales como música, literatura, teatro, medios de comunicación y sistemas informales de educación que les permiten reproducir y transmitir sus valores y sentido de pertenencia, son catalogados y tratados a partir de la pertenencia a una categoría poblacional específica. Lo anterior se manifiesta en la política oficial de asentamiento poblacional, en el sistema educativo y en las oportunidades laborales que el Estado provee a cada subgrupo diferenciado. De Lucas, citando a Mauss, recuerda que "la inmigración es un fenómeno social total, que involucra los diferentes aspectos (laboral, económico, cultural, jurídico, político) de las relaciones sociales" (De Lucas, 2003) que, para los judíos del Cáucaso, ha significado un ajuste a los patrones de la sociedad israelí sin una estructura comunitaria sólida ni el apoyo de los organismos e instituciones israelíes que ha motivado la aparición de iniciativas informales dentro del grupo.

La razón por la cual los judíos del Cáucaso fueron invisibles para la administración israelí fue que llegaron dentro de una oleada migratoria en la cual la gran mayoría de los más de 1.2 millones de judíos que emigraron a Israel desde la ex Unión Soviética eran judíos rusos askenazíes, entre ellos

\footnotetext{
${ }^{11}$ Curso en línea "The History of Modern Israel". Universidad de Tel Aviv. Coursera. Certificado obtenido el 16 de febrero de 2018.

${ }^{12}$ https://www.mfa.gov.il/mfa/mfaes/facts\%20about\%20israel/pages/adquisicin\%20de\%20la\%20nacionalidad \%20israel.aspx Consultada el 15 julio 2019.
} 
un 15 o $20 \%$ pertenece a otros grupos étnicos/lingüísticos que si bien provenían de la misma zona y eran ruso hablantes mantenían culturas, tradiciones y dinámicas familiares muy diferentes. ${ }^{13}$

\section{Discusión}

Los términos de referencia en Israel para designar y catalogar a los judíos del Cáucaso dan una pista sobre lo complejo que ha sido para el Estado israelí comprender esta migración. Dichos términos han variado y generado tensiones a lo largo del tiempo. Primero se optó por llamarlos "judíos de la montaña" término que resultaba despectivo por lo que se decidió adoptar el de "judíos soviéticos" mismo que resultaba políticamente cargado y sesgado, se prefirió "kavkazim" (palabra en hebreo que significa caucásicos) pero que enfrentaba una connotación racial y dificultaba su catalogación burocrática. Hay que destacar que estas denominaciones son externas y extrañas para los judíos del Cáucaso que se suelen autodefinir simplemente como "Juhur" (término que en tat significa "judíos").

Los judíos del Cáucaso emigraron fuertemente de la zona a partir de la década de los sesenta, sus destinos primordiales fueron los Estados Unidos e Israel debido a las oportunidades que representaba el país americano y por las presiones rusas contra sus judíos después de la guerra árabe israelí de 1967 que se saldó con una estrepitosa derrota de los aliados árabes de Moscú a manos de un Israel cada vez más próximo a los Estados Unidos. Esto creó una situación incómoda para los judíos de la Unión Soviética y es aquí cuando se registra la primera oleada migratoria hacia Israel. (Tolts, 2015)

En el caso de los "kavkazim" la categorización delineada por Kimmerling muestra sus limitaciones y es ejemplo de la invisibilización burocrática en Israel pues, por un lado los aglutina con los judíos rusos (askenazi) y se ven beneficiados de las políticas diseñadas para dicho subgrupo pero, por otro lado, sus particularidades culturales, sociales, políticas e identitarias se invisibilizan para el Estado quedando en el propio grupo de "kavkazim" la carga en el mantenimiento y transmisión de dichos valores identitarios particulares.

Bram (2009) analiza las dificultades nominativas y administrativas que enfrentan los judíos del Cáucaso ante una burocracia israelí no preparada para designar y acomodar a sus estándares a un grupo con características tan particulares. Argumenta que durante mucho tiempo la dinámica fue la de asimilarlos y definirlos administrativamente como "judíos rusos" debido a su lugar de origen (la ex URSS) y ser ruso hablantes.

En este punto es importante resaltar lo que Stephen Castles afirma en su artículo "Hierarchical Citizenship in a World of Unequal Nation-States" sobre la diferencia entre ciudadanía política (de carácter universal) y la pertenencia nacional que resulta ser culturalmente específica y exclusiva pues en el caso de los judíos del Cáucaso en Israel no tenemos un caso de discriminación legal o de negación de sus derechos amparados por la Ley del Retorno ya citada. La tensión está en que "la construcción de Estados nación democráticos comúnmente implica una asimilación compulsiva de grupos culturales minoritarios" (Stephen 2010).

\footnotetext{
${ }^{13}$ Judíos del Cáucaso, judíos de Bukhara y judíos georgianos, chechenos, dagestanos y osetios componen este heterogéneo grupo de "no rusos".
} 
Nelly Elias aborda el tema de los patrones identitarios y cómo los medios de comunicación israelí retratan a los inmigrantes de la ex URSS en Israel (Nelly, 2008). Elias, basándose en entrevistas a inmigrantes de la antigua Unión Soviética a Israel, identifica los procesos por los cuales sus patrones identitarios se ven afectados por la asimilación de formas y dinámicas sociales y culturales israelíes que los medios de comunicación emiten y fomentan. Un ejemplo paradigmático es el de la cantante israelí Sarit Hadad, nacida en 1978 con el nombre Sara Khudadatov e hija de inmigrantes originarios de Daguestán y Azerbaiyán. Al buscar ser más aceptada mediáticamente decidió cambiar su nombre a Sarit Hadad pues resultaba más atractivo en el ámbito musical al sugerir un origen mediterráneo. Hadad grabó un disco en árabe en 1997 y visitó Jordania como parte de una gira internacional y en 2002 representó a Israel en el concurso Eurovisión.

Si bien la historia de Hadad podría ser considerada un caso de asimilación y negación de la herencia caucásica paradójicamente para muchos judíos del Cáucaso simboliza un ejemplo a seguir. Uno de los entrevistados (hombre de 25 años) afirmó "Hadad es una de nosotros, ella nos representa y seguimos su carrera musical pues demuestra que nosotros podemos llegar a destacar en Israel"14 mientras dos muchachas ( 21 y 23 años) me informaron vía correo electrónico que asisten a todos los conciertos de Hadad pues "además de encantarnos sus canciones nos sentimos representados por ella"15

En Israel el ejército juega un rol político, económico y social que trasciende por mucho su función militar. En ese sentido tener héroes militares es una constante en la historia del Estado israelí. La figura de Yekutiel Adam, nieto de Yekutiel Ravayev quien muriera defendiendo el poblado de Petah Tikva en 1916, es un símbolo para la generación que migró a Israel en los setenta. Adam se enroló en la Haganah a los 15 años y luchó en todas las guerras árabes-israelíes. En 1968 fue designado comandante de la prestigiosa brigada Golani y en 1982 dirigió al Mossad. Adam moriría en 1982 en el poblado de Damour, Líbano y enterrado con todos los honores en el cementerio militar. "Yo conocí a Yekutiel Adam en el ejército, hice mi servicio militar con él" (hombre anciano de edad desconocida).

Las entrevistas e historias de vida recopiladas muestran que la primera generación nacida en Israel adopta un patrón lingüístico interesante pue si bien aprenden el hebreo y lo usan como forma de comunicación en detrimento del judeo tat y el ruso que se relegan a un ámbito familiar e informal, es esa misma generación la que crea y participa en actividades educativas informales para el aprendizaje del judeo tat y la transmisión de su herencia cultural (bailes típicos, canciones y comida)

Para dos de las entrevistadas el asistir una vez a la semana a reuniones organizadas en casas de familiares tenía implicaciones identitarias poderosas: "Somos israelíes pues nacimos aquí pero nuestros orígenes y nuestra historia están en el Cáucaso, por eso nos reunimos cuando podemos para cocinar, bailar y hablar en nuestro idioma materno" (mujer 31 años). "Yo no he viajado aún a conocer el hogar de mi familia (Georgia) pero mis padres me platican sobre los paisajes y el pueblo del cual llegaron a Israel. Soy israelí pero mi historia familiar está en el Cáucaso" (mujer 28 años).

\footnotetext{
${ }^{14}$ Entrevistas realizadas en Bakú y Tbilisi en el verano de 2014.

${ }^{15}$ Serie de correos electrónicos en 2015.
} 
Thomas de Waal en su libro "Great Catastrophe" busca entender, entre otras cosas, los patrones y dinámicas identitarias, migratorias y residenciales de los armenios sobrevivientes (y sus descendientes) al genocidio sufrido por esta nación en 1915. De Waal encuentra lo que denomina "triple patrón" en las respuestas de sus entrevistados a la pregunta "¿de dónde eres? Pues todos contestaban con tres referencias geográficas (ciudades) ${ }^{16}$ que les daban sentido de pertenencia.

En el caso de los judíos del Cáucaso entrevistados se puede encontrar una tendencia similar al "triple patrón" de De Waal en la cual ciudades como Nueva York, Estambul, Moscú, Bakú, Yerevan, Ganja, Tbilisi juegan un rol predominante en la creación del sentido de pertenencia y dinámicas migratorias de los judíos caucásicos.

Algo que destacó durante mis entrevistas y trabajo de campo fue la movilidad de algunos de los entrevistados llamando mi atención el caso de los jóvenes entre 20 y 30 años nacidos y residentes en Israel que visitaban una o incluso dos veces al año sus pueblos y ciudades de origen en Georgia y Azerbaiyán. Algunos de ellos planeaban casarse en el mismo pueblo en el cual sus padres y abuelos habían vivido. "Vengo de vacaciones de verano a la aldea de mi familia. Aquí me encuentro con primos y primas que viven en Moscú y Estados Unidos y convivo con ellos durante el periodo vacacional en la casa familiar y busco novia para comprometerme" (hombre 26 años). "Estoy comprometido para casarme desde hace dos años, mi pareja y yo estamos ahorrando para poder casarnos en el mismo lugar que mis padres lo hicieron" (hombre 27 años).

Otro factor a subrayar son las redes transnacionales informales (principalmente de negocios) que los empresarios pertenecientes a la comunidad caucásica mantenían con socios en Bakú, Tbilisi, Nueva York y Moscú. Algunos de ellos incluso tenían estancias largas en dichas ciudades "por negocios" y enviaban constantemente dinero a sus familias residentes en Israel. El caso más interesante fue el de un vendedor de electrónicos que pasaba la mitad del año en Nueva York y la otra parte la dividían entre Israel y Azerbaiyán y que me confesó que asistía a la sinagoga de Bakú no tanto para rezar sino para socializar. "En Israel no suelo ir tanto al templo pues estoy acompañado de mi familia pero cuando estoy de viaje encuentro a amigos y parientes en la sinagoga y así no me siento tan solo" (hombre 45 años). (Bram, 2009).

La sinagoga parece ser un lugar estratégico para la preservación de los lazos comunitarios y la identidad etno-religiosa tanto en el Cáucaso como en los otros países de migración de los kavkazim. Bram (2009) encuentra que es en las sinagogas de Nueva York y Moscú en donde se reproducen los signos religiosos distintivos del grupo, su simbología propia (imágenes de sinagogas del Cáucaso adornando los templos neoyorquinos y moscovitas) y un espacio comunitario que da cohesión al permitir que se produzcan noviazgos, matrimonios y nacimientos dentro del grupo. Los diferentes grados de endogamia de los judíos del Cáucaso se explican por varios factores entre ellos: lugar de migración (suelen ser menos endógamos en Estados Unidos que en Rusia), brecha generacional (la primera generación nacida fuera del Cáucaso es menos endógama que sus padres) y status socio económico. "Yo me casé con una ashkenazí, tuve problemas con mi familia al principio pues ellos son más conservadores pero ahora tenemos una familia normal y a mi esposa la reciben en la casa

\footnotetext{
${ }^{16}$ Ejemplos de las respuestas son: Sivas-Jerusalén-Queens; Urfa-Beirut-Manhattan; Maras-Beirut-New Jersey.
} 
de mis padres y en la sinagoga" (hombre 45 años). Parece ser que el tabú del matrimonio exogámico se diluye con el paso de las generaciones.

Algunos líderes comunitarios han establecido y creado proyectos para lidiar con la invisibilidad y falta de cohesión interna del grupo caucásico. Algunos de los mecanismos que han establecido e implementado los judíos del Cáucaso tanto residentes en Israel como en Azerbaiyán y Georgia para preservar la cohesión del grupo carecen de estructura y un nivel de organización elevado y se constriñen a unas pocas personas y en un ambiente informal, ejemplo de esto son los grupos de WhatsApp y Telegram; foros de internet en los cuales se comparte información, se solicita ayuda y se avisa de viajes de sus miembros. "Me reúno una vez a la semana con mis amigos para jugar ajedrez, tomar cerveza y platicar de la familia en Azerbaiyán y Daguestán" (hombre 55 años).

Uno de los proyectos más estructurados y formales que encontré es el "Museo de David Baazov de Historia del judaísmo de Georgia y relaciones judío-georgianas" ubicado en la calle Anton Katalikosi en la ciudad de Tbilisi. ${ }^{17}$ En dicho museo se exhiben de manera permanente trajes típicos, artesanía y fotografías de las comunidades judías del Cáucaso en general y de Georgia en particular. El museo se establece como un referente para la generación nacida en Israel y que busca acercarse a la historia de sus antepasados.

Una de las iniciativas que reúnen a judíos del Cáucaso a nivel internacional es el World Congress of Caucasus Jews que se lleva a cabo anualmente desde el 2002 en Tel Aviv. ${ }^{18}$ Si bien los organizadores principales son judíos residentes en Moscú asisten representantes de las comunidades de Israel, Estados Unidos y los países caucásicos. Una de las iniciativas de dichos congresos fue el fórum virtual Juhuro.com que funcionó hasta el 2013 (la página está en reconstrucción desde hace años) y que organizaba reuniones literarias virtuales, foros de discusión de tópicos comunitarios. "Participábamos en los foros de discusión virtuales porque era una manera de conocer a mujeres solteras" (hombre 24 años); "en los foros podías averiguar las opiniones de la chicas en temas como el sexo fuera del matrimonio, y si se casarían con alguien no perteneciente a su etnia (refiriéndose a los judíos rusos)" (hombre 27 años).

Durante la estancia de investigación los entrevistados hacían énfasis en la importancia del cementerio por lo cual se visitó el panteón de Bakú con un guía-intérprete (muy poca gente en Azerbaiyán habla inglés fuera del ámbito académico y político). Durante la visita se pudo constatar, platicando con los sepultureros, que algunos de los ahí enterrados habían vivido en Israel y regresaron a pasar sus últimos años a su pueblo de origen. Si bien no es posible hablar de una dinámica colectiva recurrente sí llama la atención el número de personas enterradas que habían emigrado a Israel, se habían establecido ahí por varias décadas y retornaron a su pueblo de origen a jubilarse y morir.

\section{Conclusiones}

\footnotetext{
${ }^{17}$ https://www.facebook.com/jewishgeo/ Página de Facebook del museo.

${ }_{18}$ Parece que el Congreso se ha dejado de llevar a cabo desde 2017, otras fuentes aseguran que aún se lleva a cabo pero cambia de sede. Ha sido difícil corroborar esta información.
} 
La emigración de los judíos caucásicos hacia Israel marcó un hito en su historia y representó un desafío para un Estado israelí que siendo un país multicultural se mostró no preparado para integrar a este grupo. La razón, como se ha demostrado en el texto, es el proceso de invisibilización al subsumirse al grupo kavkazim como parte de la migración "rusa". La burocracia y el sistema migratorio perpetuó esta invisibilización cultural al tender a la asimilación de los judíos del Cáucaso a una nacionalidad rusa construida por razones de eficiencia y registro a lo que se suma la inexistencia de una élite académica y política propia que expusiera y luchara por el respeto de las diferencias culturales del grupo.

Los kavkazim encontraron en Israel un Estado que, si bien estaba abierto económica y legalmente a su inmigración, su sistema cultural, político y educativo resultaba cerrado y hostil pues fue establecido por y para judíos askenazíes por lo que los mismos respondían a sus dinámicas y necesidades particulares. La identidad de los judíos del Cáucaso se vio cuestionada, amenazada y limitada por las circunstancias de su emigración a Israel pero fueron las mismas condiciones de la sociedad receptora las que permitieron la reformulación y redefinición de dicha identidad por canales desconocidos e inexplorados en su región de origen. La complejidad es aún mayor porque a diferencia de otros subgrupos poblacionales como drusos, judíos etíopes y mizrahim, los judíos del Cáucaso carecen de cualquier mecanismo o representación legal en el entramado institucional israelí y han optado por apoyar a los partidos políticos, asociaciones civiles y representantes comunales oficiales de la comunidad rusa lo que incrementa su invisibilización.

Como los ejemplos de Hadad y Adam demuestran los judíos del Cáucaso han buscado integrarse, y en cierto nivel asimilarse, lingüística, cultural y socialmente en los espacios de socialización claves israelíes como son el ejército y el ámbito artístico, sin embargo hay áreas como el espacio político formal y el académico en donde los kavkazim son prácticamente inexistentes lo que impide que el grupo adquiera una visibilización mayor.

La cultura en Israel tiende a florecer gracias a contradicciones y tensiones entre grupos diferenciados. En el caso de los judíos del Cáucaso en Israel, sus costumbres colectivas experimentaron una reformulación precisamente por la tensión generada por su encuentro y convivencia con otros grupos de la sociedad israelí, reformulación que, por un lado significó asimilarse a la misma en varios aspectos pero, por otro implicó asumir una alteridad hasta entonces no percibida como tal.

Este es un buen caso de estudio en el cual una administración ciega en sus procedimientos formales a ciertas diferencias lingüísticas, culturales y sociales al interior del grupo migratorio crea lo que se puede definir como una "identidad reactiva politizada" pues, como se señaló anteriormente, si bien los judíos del Cáucaso llegaron a Israel como parte de la "aliyah rusa" al catalogarlos sin reconocerles legal y formalmente sus particularidades etno-culturales, se provocó que este grupo migrante minoritario y subsumido comenzara a reclamar espacios en la esfera pública y en medios de comunicación.

La conexión transnacional que los judíos del Cáucaso han logrado establecer demuestra que los grupos migratorios ignorados administrativamente por la burocracia de los países receptores pueden establecer dinámicas, crear estrategias y mecanismos de preservación y transmisión de valores 
culturales de manera informal pero efectiva al mismo tiempo que se integran a la sociedad receptora.

Hay una constante trágica a lo largo de la historia de los judíos del Cáucaso: siempre han sido narrados, descritos y catalogados por un otro. Nunca han sido comprendidos y estudiados a partir de sus propios conceptos y definiciones. Su invisibilización se ahonda por la carencia de una organización social interna y por una cohesión que se limita al espacio privado y que a su vez pareciese que la pregunta ¿quiénes somos? ha estado ausente apareciendo recién al enfrentarse a una alteridad que los fuerza a definirse.

\section{Bibliografía}

- Libros

De Waal, Thomas. Great Catastrophe. Armenians and Turks in the Shadow of Genocide. Oxford University Press. New York. 2015.

De Waal Thomas. The Caucasus. An Introduction. Oxford University Press. New York. 2010.

Kimmerling, Baruch. (1988). The Israeli State and Society. Boundaries and Frontiers. SUNY series in Israeli Studies.

Johnson, Paul. La historia de los judíos. Ediciones B. Barcelona. 2003.

- Artículos académicos

Borjian, Habib. (2015). Judeo-Iranian Languages en Aaron D. Rubin y Lily Kahn, eds. A Handbook of Jewish Languages, Brill, pp 234-295.

Bram, Chen. (2009). Immigrant Jews of the Cuacasus in New York and Moscow: Ethno-Cultural Identity and Community Organization en Between Tradition and Modernity. The Plurality of Jewish Custums and Rituals. Sociological, 13. 2009.

Bram, Chen. (2009). Caucasus Jews and their Neighbors: Social Network in a Multi-Ethnic Society en Ergun Ozgur ed. The North Caucasus Histories. Diasporas and Current Challenges. The Social Sciences Research Council. New York, EUU.

Bram, Chen. The Catch 22 of Categorization: Soviet Jews, Caucasus Jews, and Dilemmas of Multiculturalism in Israel en Cultural Education, Cultural Sustainability: Minority, Diaspora, Indigenous and Ethnoreligious Groups in Multicultural Societies.2008.

Castles, Stephen. (2005). Hierarchical Citizenship in a World of Unequal Nation-States. Political Science and Politics, 38 (4). 
De Lucas, Javier. (2003). Inmigración y globalización acerca de los presupuestos de una política de inmigración. Redur 1.

Elias, Nelly. (2005). Between Russianness, Jewishness and Israeliness. Identity patterns and media uses of the FSU immigrants in Israel en Journal of Jewish Identities, 4 (1), 93-102.

Kaganovitch, Albert. (2011) Genealogy of Bukharan Jewry. Genealogical Sources and Issues en Israel Genealogy Society. Tel Aviv, Israel.

Sayad, Abdelmalek. Estado, nación e inmigración. El orden nacional ante el desafío de la inmigración. Apuntes de investigación. ISSN 0329-2142 Número 13.

Tolts, Mark. Post-Soviet Aliyah and Jewish Demographic Transformation. Paper presentado en el 15th Congreso Mundial de Estudios Judíos. 2-6 agosto 2009.

Páginas internet

https://www.mfa.gov.il/mfa/mfaes/facts\%20about\%20israel/pages/adquisicin\%20de\%20la\%20naci onalidad\%20israel.aspx Consultada 15 julio 2019.

https://www.facebook.com/jewishgeo/?epa=SEARCH_BOX 